\title{
Els errors en el sistema verbal dels estudiants de català com a llengua estrangera
}

\author{
Mireia Toda Cosi \\ University of Maryland, College Park \\ todacosi@umd.edu
}

Rebut: 2 de març de 2021

Acceptat: 22 de juny de 2021

\section{Resum}

L'objectiu d'aquest estudi és caracteritzar el sistema verbal de quatre interllengües d'aprenents de català: la de parlants de castellà i gallec, d'italià, de francès i d'anglès. Després d'identificar les característiques de cada sistema verbal, la finalitat és comparar quines característiques són qualitativament similars independentment de la primera llengua dels parlants. Per assolir el propòsit, s'ha analitzat una mostra de 48 escrits d'estudiants de català tant en context d'immersió com a l'estranger, el nivell dels quals va des de l'A2 al B1 alt-B2 baix del Marc europeu comú de referència (MECR). Les diferències es descriuen d'acord amb les variacions amb relació al temps, l'aspecte, el mode, l'ús de verbs buits, el règim verbal, l'ús de perífrasis verbals i la concordança. Les dades s'adrecen des del marc teòric de la transferència a terceres llengües i la teoria de la processabilitat (Pienemann, 1998). Havent observat les idiosincràsies i les similituds de les diverses interllengües, s'arriba a la conclusió que l'aspecte, l'ús dels verbs buits i les perífrasis verbals són característiques comunes, malgrat haver-hi diferències qualitatives entre elles. Es raona que els errors de la mostra s'expliquen millor dintre del marc de la teoria de la processabilitat que en el del model de preeminència tipològica (Rothman, 2011) i el model de proximitat lingüística (Westergaard, 2011) i es consideren les implicacions dels resultats de cara a futures línies de recerca i el desenvolupament de materials didàctics.

\section{Paraules clau}

Interllengua, CLE, català, verbs, sintaxi

\begin{abstract}
The goal of this study is to characterize the interlanguage verb system of Catalan learners with different first languages (L1s): Spanish and Galician, Italian, French, and English. After identifying the features of each verb system, the goal is to compare which characteristics are qualitatively similar regardless of the L1. To this end, 48 writing samples from learners of Catalan were analyzed. Learners varied in their learning context (immersion in Catalonia versusclassroomsabroad), and theirproficiency (from A2 to high-B1/low-B2 according to the Common European Framework of Reference [CEFR]). Differences in the verb systems are described based on deviations in tense, aspect, mode, usage of delexical verbs, verbs' selectional restrictions, usage of verb phrases, and agreement. The data are analyzed within the framework of L3 transfer and Processability Theory (Pienemann, 1998). Having observed the particular traits and similarities across the analyzed interlanguages, I conclude that the elements that vary from Catalan similarly across interlanguages are aspect, usage of delexical verbs, and verb phrases; despite there being minor qualitative differences. I argue that the learners' errors are best explained within the framework of Processability Theory rather than L3 models such as the Typological Primacy Model (Rothman, 2011) and the Linguistic Proximity Model (Westergaard, 2011). Lastly, the implications of the results are discussed regarding future research and the development of teaching materials.
\end{abstract}

\section{Key words}

interlanguage, Catalan as a foreign language, verbs, syntax 


\section{Introducció}

Aquest treball investiga les particularitats del sistema verbal que els parlants d'anglès, espanyol, francès, gallec i italià com a primera llengua (L1) utilitzen durant l'adquisició del sistema verbal del català com a llengua estrangera (LE). Utilitzo el terme LE per referir-me a la llengua que s'aprèn durant l'edat adulta independentment del context, sense distingir entre immersiu o no, o l'ordre d'adquisició. L'estudi té dos objectius: (1) caracteritzar el sistema verbal de la interllengua (IL) catalana dels estudiants a través de la comparació entre la llengua meta (LM), el català, i les llengües dels participants, i (2) esbrinar si hi ha trets comuns entre els sistemes verbals de les ILs independentment de l'L1 dels alumnes.

Per poder dur a terme l'anàlisi, la introducció examina els conceptes que contribuïren a la constitució de la noció d'interllengua (Selinker, 1972) i les teories que se n'han derivat. Aquest projecte vol explorar les similituds en el desenvolupament lingüístic d'estudiants amb diverses L1s.

\subsection{Els orígens de la interllengua}

Els orígens de la interllengua es remunten als anys $50 \mathrm{amb}$ l'aparició de l'anàlisi contrastiva (Lado, 1957), que pretenia preveure les dificultats i facilitats durant el procés d'aprenentatge a còpia de comparar l'L1 i la LM. L'objectiu era anticipar-se als errors dels estudiants, que eren percebuts negativament. Aquest plantejament donà peu a l'anàlisi d'errors (Corder, 1967), en què els errors es consideraven necessaris i un reflex de l'etapa (o estadi o seqüència) natural d'aprenentatge sense atributs negatius. Finalment, Selinker (1972) proposà el concepte d'interllengua, que definí com un sistema amb coherència interna que ens permet observar el desenvolupament progressiu d'una L2 a mesura que l'estudiant va aprenent. Segons l'autor, les dades necessàries per observar la interllengua són les que resulten de l'esforç d'un adult per transmetre un significat en una llengua meta. En resum, Selinker advocava per observar els intents d'expressió en la LM per accedir a un sistema lingüístic diferenciat de l'L1 i la llengua meta: la interllengua (IL).

Després de la contribució de Selinker, aquesta línia de recerca quedà estancada, probablement per la complexitat de la qüestió, l'absència de noves teories i la quantitat d'errors que raïen inexplicables a través de la transferència lingüística. En els últims vint anys, han sorgit dos tipus de teories que han intentat adreçar la IL: les que s'han centrat en fenòmens de transferència lingüística i les que han documentat el desenvolupament de la IL com a sistema independent.

L'origen de la majoria de teories basades en transferència lingüística rau en l'observació de l'adquisició d'L2s. Tanmateix, com que el català après com a LE sol ser, almenys, tercera llengua (L3), tan sols adreço teories d'adquisició d'L3s. La distinció entre L2 i L3 és necessària perquè quan aprenem una L2 tan sols tenim experiència adquirint la nostra L1, però amb una L3 ja hem après una llengua més enllà de la materna. A més a més, en el cas d'una L3, la transferència lingüística pot provenir tant des de l'L1 com l'L2; mentre que en el cas de l'L2, l'única llengua disponible és l'L1. La majoria de teories que adrecen aquesta qüestió es poden dividir en dues posicions: la transferència lingüística prové d'una única llengua o bé de les dues (l'L1 i l'L2).

Les teories que defensen la transferència completa des d'una sola llengua assumeixen que l'L1 o l'L2 es "duplica" i serveix com a patró per a l'L3, que va ajustant-ne els paràmetres lingüístics progressivament. Les hipòtesis principals basades en aquesta premissa són l'estatus de l'L2 (EL2, Bardel i Falk, 2007) i el model de preeminència tipològica (MPT; Rothman, 2011). L'estatus de l'L2 proposa l'L2 com a font de transferència lingüística durant les primeres etapes d'aprenentatge perquè el procés d'adquisició d'una L3 s'assembla més al d'una L2 que al de l'L1. Per contra, el model de preeminència tipològica argumenta que el sistema lingüístic més 
semblant tipològicament és el que es transfereix en estadis inicials. És a dir, tant un parlant nadiu d'anglès amb L2 castellana com un nadiu de castellà amb L2 anglesa transferirien el castellà si aprenguessin el català com a L3. Rothman (2015) explica que se segueix una jerarquia a l'hora de decidir quina llengua és més similar tipològicament: primer l'aprenent compara el lèxic i, si no hi ha similituds, passa a comparar altres aspectes lingüístics (fonologia, morfologia i sintaxi, en aquest ordre). El problema d'ambdues teories és que tan sols adrecen els estadis inicials d'aprenentatge i no expliquen on comença i acaba aquest "estadi inicial".

Dues propostes més recents argumenten que no es transfereix el sistema lingüístic sencer al principi, sinó característiques lingüístiques concretes de l'L1 i l'L2. Aquestes teories són el model de proximitat lingüística (MPL; Westergaard, Mitrofanova, Mykhaylyk i Rodina, 2016) i el model de l'escalpel (Slabakova, 2017). L'MPL parteix de la mateixa idea que el model de Rothman, però proposa que la similitud d'una característica lingüística concreta amb la de la LM determina què es transfereix; en altres paraules, tan sols es transfereixen característiques específiques de l'L1 o l'L2 que l'estudiant percep com a semblants a les de l'L3. El model de l'escalpel afegeix complexitat a aquesta idea, argumentant que altres factors també juguen un paper a l'hora de decidir la propietat o la llengua que es transfereix, com ara el nivell d'activació de la llengua (per exemple, la llengua que s'acaba d'utilitzar o la que més s'empra). Tanmateix, aquest article se centra en el model de proximitat lingüística perquè els participants d'aquest estudi tenen rerefons massa heterogenis i no se n'han pogut recollir prou detalls per adreçar el nivell de complexitat que advoca el model de l'escalpel.

Les teories que observen la IL com a sistema independent se centren en etapes de desenvolupament lingüístic, és a dir, l'ordre en què s'adquireixen les propietats de la LM. L'avantatge d'aquest punt de vista és que permet trobar seqüències de desenvolupament comunes independentment de l'L1 i explicar per què hi ha elements que no s'adquireixen amb facilitat malgrat coincidir en l'L1 i la LM. La més rellevant per a aquest estudi és la teoria de la processabilitat (TP; Pienemann, 1998), ja que abasta el sistema complet de la interllengua. Una altra teoria d'interès seria la hipòtesi aspectual (HA; Andersen, 2002); ${ }^{1}$ tanmateix, l'HA no s'ha utilitzat per a l'anàlisi perquè l'objectiu del treball és caracteritzar tot el sistema verbal, no tan sols l'aspecte. A més, les dades de què es disposa no són longitudinals, com caldria per investigar la hipòtesi. Tanmateix, el lector pot consultar una revisió recent de l'HA a BardoviHarlig i Comajoan-Colomé (2020).

Segons la TP (Pienemann, 1998), els estudiants no poden utilitzar característiques lingüístiques que no poden processar, és a dir, interpretar; per exemple, si l'aprenent no reconeix cantava com a temps de passat, no podrà utilitzar-lo correctament. Pienemann i Lenzing (1998: 159; traducció de l'original) ho descriuen així: "La lògica darrere la TP és la següent: en qualsevol estadi de desenvolupament l'aprenent pot produir i entendre tan sols aquelles formes de l'L2 que l'estadi actual del processador lingüístic pot gestionar." Aquest "processador lingüístic" seria l'equivalent humà d'un ordinador pel que fa al llenguatge. La teoria suposa que el procés d'aprenentatge segueix un ordre natural estratificat que reflecteix una trajectòria de desenvolupament. Aquestes etapes se succeeixen i no es pot avançar a la següent sense haver assolit l'anterior. És a dir, hi ha un ordre concret que determina l'ordre en què es poden adquirir les característiques d'una llengua. Un paral-lelisme amb les matemàtiques ens pot ajudar a entendre-ho. No es pot aprendre a multiplicar sense haver après a sumar, per tant, l'estadi "suma" precedeix l'estadi "multiplicació"; alhora, "multiplicació" precedeix "divisió" etc. En relació amb la llengua castellana, Bonilla (2015a) mostra que la marca de plural precedeix la concordança atributiva pel que fa a la morfologia, pertanyent cada element

1 La hipòtesi aspectual se centra en l'emergència de la morfologia aspectual, segons la qual la morfologia perfectiva precedeix la imperfectiva. Argumenta que aquest canvi es percep primer en predicats tèlics i després en predicats atèlics. Tanmateix, aquesta explicació és una sobresimplificació i el lector hauria de referir-se a Andersen (2002). 
als estadis 2 i 3, respectivament. En canvi, el subjuntiu se situa al cinquè nivell i implica l'adquisició satisfactòria dels estadis previs (Figura 1).

\begin{tabular}{|l|l|l|l|}
\hline Estadi & Processos & Sintaxi & Morfologia \\
\hline 5 & $\begin{array}{l}\text { Procés d'intercanvi } \\
\text { d'informació entre } \\
\text { proposicions }\end{array}$ & $\begin{array}{l}\text { Subjuntiu } \\
\text { Concordança entre } \\
\text { oracions de relatiu }\end{array}$ \\
\hline 4 & $\begin{array}{l}\text { Procés entre frases d'una } \\
\text { mateixa proposició }\end{array}$ & $\begin{array}{l}\text { Inversió SV } \\
\text { Us de clítics }\end{array}$ & $\begin{array}{l}\text { Concordança amb el } \\
\text { complement directe } \\
\text { Concordança amb el } \\
\text { complement predicatiu }\end{array}$ \\
\hline 3 & Procés a nivell de frase & $\begin{array}{l}\text { Adjunció de frases } \\
\text { preposicionals i altres adjunts } \\
\text { abans del verb (o subjecte) }\end{array}$ & $\begin{array}{l}\text { Concordança SN } \\
\text { (atributiva) }\end{array}$ \\
\hline 2 & Procés de categoria & Ordre canònic (SVX/VX) & Marca de plural -s \\
\hline 1 & Accés al lemma & & Mots \\
\hline
\end{tabular}

Figura 1. Seqüències de desenvolupament de l'espanyol, adaptat de Bonilla (2015b, p. 211)

\section{L'estudi}

L'objectiu d'aquest estudi és investigar de manera qualitativa i exploratòria les qüestions següents:

1. És possible explicar totes les diferències entre el sistema verbal català i el de la IL dels parlants de castellà-gallec, d'italià, francès i anglès segons la transferència lingüística?

$\mathbf{H}_{1 . a}$ : Sí, la transferència des de la llengua tipològicament més similar explica la majoria dels errors (model de preeminència tipològica; Rothman, 2011).

$\mathbf{H}_{1 . b}:$ Sí, la transferència prové de llengües apreses amb anterioritat depenent de la propietat lingüística (model de proximitat lingüística; Westergaard et al., 2016).

$\mathbf{H}_{1 . c}:$ No, els errors reflecteixen seqüències d'adquisició naturals (teoria de la processabilitat; Pienemann, 1998).

2. Hi ha propietats del sistema verbal comunes en la IL dels aprenents de català independentment de l'L1?

$\mathbf{H}_{2 . \mathrm{a}}:$ Sí, aquestes propietats existeixen i es deuen a seqüències naturals de desenvolupament que prevalen per s obre de la transferència (teoria de la processabilitat; Pienemann, 1998).

$\mathbf{H}_{2 . \mathrm{b}}$ : No, aquestes propietats no existeixen i les diferències les causen altres factors com ara la transferència lingüística des d'altres llengües apreses prèviament.

\section{Metodologia}

\subsection{Participants}

El treball analitza mostres de 42 participants que completaren 49 redaccions (Taula 1). Les mostres foren obtingudes durant el curs 2015-16 a través d'universitats amb programes de l'Institut Ramon Llull, el Servei Lingüístic de la Universitat Rovira i Virgili, i l'Escola Oficial d'Idiomes de Tarragona. Originalment es volia recollir una mostra més homogènia d'estudiants aprenent català a l'estranger; tanmateix, l'obtenció fou inviable a causa d'incompatibilitat dels 
calendaris acadèmics, dificultats a l'hora de contactar amb el professorat, pocs participants amb el perfil adequat, insuficient temps durant les classes i pocs voluntaris. El resultat és una mostra més heterogènia del que seria aconsellable, tant pel que fa al nivell com a les condicions d'aprenentatge i al model d'exercici. Això fa que els resultats no es puguin generalitzar a una població més gran, però també reflecteix la realitat dels estudiants de català com a LE.

Alguns participants completaren un formulari amb el perfil lingüístic, que incloïa l'edat d'aprenentatge del català, el nivell, la quantitat d'exposició i ús, la motivació, la identificació amb la cultura catalana i altres LEs que sabessin. Malauradament, el professorat no pogué administrar el formulari en tots el casos, així que les dades demogràfiques es basen en els pocs participants que l'ompliren ( 5 d'L1 castellana, $5 \mathrm{~d}$ 'L1 gallega, i 1 d'L1 italiana). Tots els participants tenien el català com a, almenys, tercera llengua, i la majoria de llengües comunes eren el castellà i l'anglès. Entre d'altres, trobem que també es parla gallec, alemany, italià o llengua de signes catalana. Aquesta distribució demogràfica exemplifica que el català rarament és una L2. La mitjana d'edat és d'uns trenta anys i el nivell dels estudiants varia entre A2 i B1 alt-B2 baix del MECR.

Taula 1. Procedència de les dades

\begin{tabular}{|l|l|l|l|l|l|}
\hline \multicolumn{7}{|c|}{ Llengua $^{\mid}$} & Italià & Castellà $^{\star}$ & Gallec & Anglès & Francès \\
\hline $\begin{array}{l}\text { Participants fora de } \\
\text { Catalunya }\end{array}$ & 6 & 0 & 5 & $\begin{array}{l}\text { 6 Regne Unit } \\
5 \text { Estats Units }\end{array}$ & 13 \\
\hline $\begin{array}{l}\text { Redaccions per parti- } \\
\text { cipant }\end{array}$ & 1 & 0 & 1 & 1 & 1 \\
\hline $\begin{array}{l}\text { Participants a Cata- } \\
\text { lunya }\end{array}$ & 1 & 6 & 0 & 0 & 0 \\
\hline $\begin{array}{l}\text { Redaccions per parti- } \\
\text { cipant }\end{array}$ & 2 & 2 & 0 & 0 & 0 \\
\hline Total de redaccions & 8 & 12 & 5 & 11 & 13 \\
\hline
\end{tabular}

${ }^{\star}$ El total per a castellà és 17 , ja que castellà i gallec s'han combinat en l'anàlisi perquè els parlants gallecs són bilingües.

\subsection{Tasques}

Les tasques confeccionades per a l'estudi avaluaven la competència escrita. Malgrat que diversos autors argumenten que la llengua oral reflecteix amb més fidelitat el coneixement lingüístic implícit (Ellis, 2005), recollir mostres orals es considerà massa arriscat, especialment sense tenir accés directe als participants. Els problemes que s'anticiparen foren els següents: manca de qualitat de les gravacions, poca naturalitat d'un monòleg i efectes en el nivell d'ús (és a dir, que el parlant baixés el nivell per acomodar un interlocutor de menys nivell), la inintel-ligibilitat de la producció, les dificultats en l'articulació de sons a nivells més bàsics i la subjectivitat a l'hora d'interpretar les gravacions. Per contra, la modalitat escrita evita la presència d'errors causats pel nerviosisme i l'espontaneïtat de l'oralitat. En aquest aspecte, en els casos en què es participava voluntàriament, s'emfatitzà que la tasca no comptava per a nota i que haurien d'evitar l'ús d'apunts o diccionaris per aconseguir redaccions que reflectissin el coneixement real dels participants.

Originàriament, es planificà d'administrar dues tasques escrites i dos formularis sobre el perfil lingüístic, un a l'alumnat i un al professorat. Malauradament, no tothom completà totes les parts. El professorat fou contactat en línia a través de les adreces electròniques disponibles al web de l'Institut Ramon Llull. A causa dels motius descrits a la secció 3.1., dels 100 professors 
contactats, tan sols sis hi contribuïren. El professorat rebé els exercicis i formularis en Word i PDF per correu electrònic i ells mateixos trameteren els documents a l'alumnat, que havia de completar-los a casa per no ocupar hores lectives. A criteri del docent, l'alumnat els retornava els escrits o me'ls enviaven directament.

Les dues redaccions (vegeu les Figures 2, 3 i 4) agrupen característiques gramaticals fins al nivell B2 amb coherència, sense demanar als alumnes activitats massa llargues que podrien descoratjar-los i frustrar-los. Per evitar que se sentissin desorientats, els enunciats eren detallats, però es donava l'opció d'escriure sobre un altre tema mentre utilitzessin les característiques lingüístiques de la llista. Els ítems gramaticals més senzills figuren en el primer exercici i els més avançats, en el segon. Les tasques reflecteixen els coneixements dels nivells A2 i B1 del MECR segons la Direcció General de Política Lingüística de la Generalitat de Catalunya al Programa de la llengua catalana per als nivells inicial (A1), elemental (A2) i bàsic (B1). Aquests nivells abasten des d'un usuari bàsic a un d'independent que ja pot expressar idees i experiències pròpies autònomament.

Has d’escriure una redacció que tingui un mínim de 130-200 paraules (no passa res si no hi arribes exactament o ho fas més llarg) $\mathrm{i}$ intentar fer servir els trets gramaticals que s'hi demanen. Utilitza aquells elements que hagis treballat a classe i/o coneguis, NO cal que els facis servir tots.

Intenta utilitzar frases fetes o expressions genuïnament catalanes que coneguis. No tinguis por de fer descripcions o introduir-hi diàlegs. Procura escriure d'una manera fluïda, utilitza conjuncions.

Figura 2. Descripció de l'activitat presentada amb els dos enunciats

\section{Exercici 1}

Escriu un correu electrònic a una amiga explicant-li què has fet avui i el viatge que vas fer aquest estiu a algun lloc de parla catalana que la teva amiga no coneix, descriu el lloc on vas estar. Al final pregunta-li què ha fet ella, com està...

Combina-hi els temps de present i passat, si ho vols, pots escriure sobre un altre tema, però recorda intentar utilitzar tants ítems com puguis de la següent llista:

Temps verbals:

-Present d'indicatiu (canto, cantes...)

-Passat perifràstic (vaig cantar, vas cantar...)

-Passat imperfet (cantava, cantaves...)

- Pretèrit perfet (he cantat, has cantat...)

-Pretèrit plusquamperfet (havia cantat, havies cantat...)

Adjectius

Possessius (meu, teu, seu...)

Preguntes (pronoms interrogatius: què, qui, quan, on, quin/a...)

Figura 3. Enunciat del primer exercici 


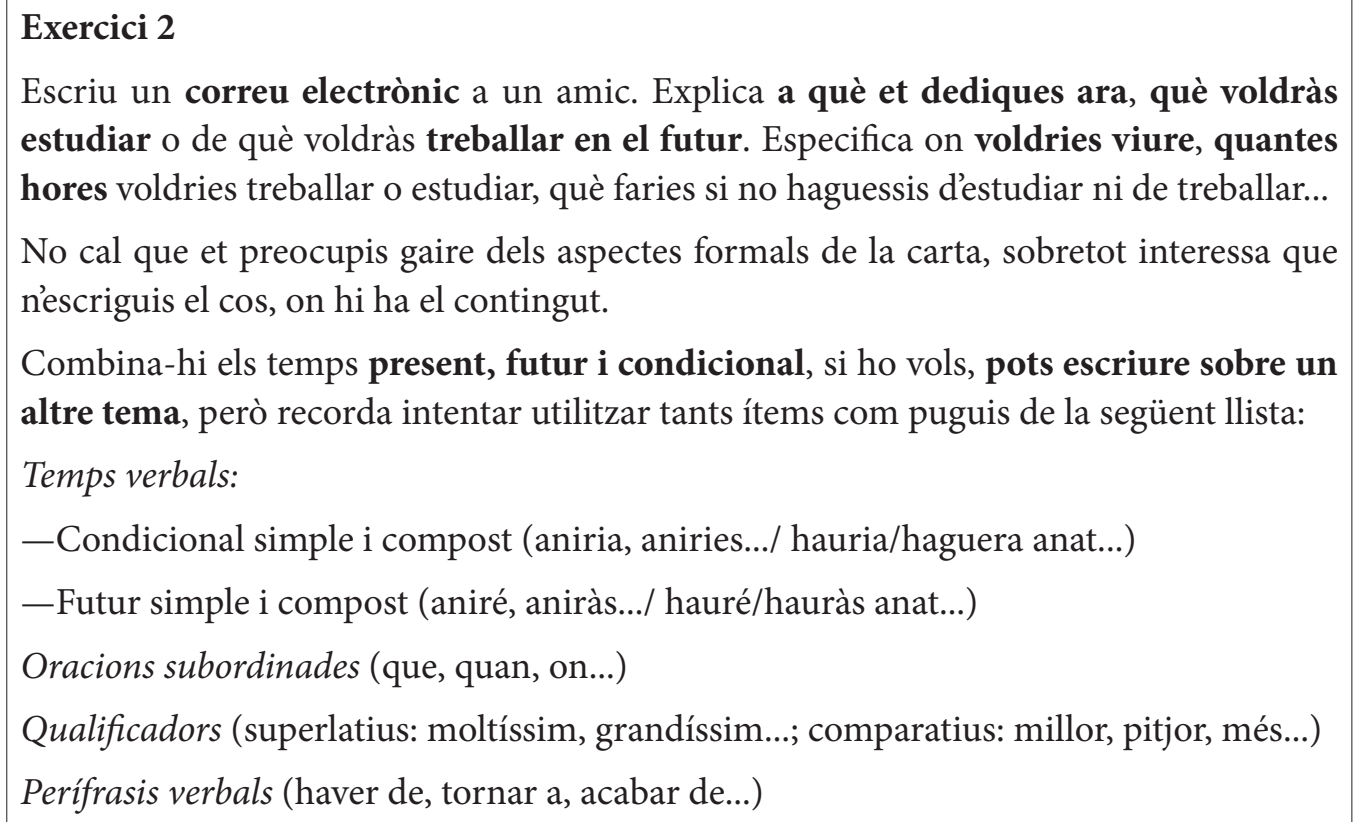

Figura 4. Enunciat del segon exercici

A causa de les dificultats durant la recollida de dades, 17 redaccions es basen en el primer exercici, 14 en ambdós enunciats i 15 són activitats que el professorat havia programat dins de l'assignatura. La comparació entre redaccions és possible perquè cada grup tenia el mateix professor, per tant, tots aquells qui seguiren instruccions diferents compartiren el mateix enunciat i L1.

\subsection{Procediment, anàlisi i organització dels resultats}

L'anàlisi de dades descriu les discrepàncies entre el sistema verbal de la IL dels parlants de cada L1 de l'estudi (italià, castellà i gallec, anglès i francès) i l'estàndard oriental del català. Aquesta varietat s'ha escollit com a referència perquè la majoria de docents de la mostra ensenyen aquest dialecte i utilitzen el llibre Veus de la mateixa varietat. L'anàlisi es basa en errors d'ús i la dugué a terme l'autora. Una redacció fou analitzada per un altre investigador i comparada amb els resultats obtinguts, cosa que va mostrar que no hi havia discrepàncies. En cas de dubte a l'hora de classificar els errors, l'autora consultà l'altre investigador fins arribar a un consens.

Per a l'anàlisi, els resultats es presenten en un apartat per a la IL de cada grup de parlants d'una L1. Cada apartat es divideix en seccions que descriuen diversos aspectes dels verbs: temps, aspecte, mode, verbs buits (verbs que no tenen un significat concret, com ara fer o haver-hi), règim, perífrasis i concordança. En cada secció es presenten els errors en una taula en l'ordre que es trobaren a la mostra. Si una IL no es diferencia del català en una característica, s'omet l'apartat. Els resultats són qualitatius i cada secció recull tots els errors d'ús de la mostra; si n'hi ha més de cinc, es reprodueixen tan sols els cinc exemples més interessants i s'indica entre parèntesis el còmput total de casos a la taula a la columna del fenomen; per exemple, distinció perfet-perfectiu (11). Al cos del text, quan és pertinent, també s'indica entre parèntesis el total d'errors de cada tipus després d'anomenar el fenomen. Hi ha errors que no es poden jutjar sense veure el context de l'escrit sencer; en aquests casos el lector pot trobar les redaccions senceres a l'annex ${ }^{2}$. S'ha indicat quan la causa de l'error podria ser transferència de l'L1, però també s'han considerat altres possibles causes, com ara seqüències de desenvolupament de l'aprenent; el principi one-to-one d'Andersen (1984), és a dir, en la interllengua, un significat concret s'expressa amb una única forma lingüística; la instrucció; o el principi de simplificació en el desenvolupament de les ILs. Per determinar si l'origen podria ser la transferència negativa (TN), s'ha comparat l'ús amb el de l'L1 i l'L2. Finalment, les similituds i diferències dels sistemes verbals de les ILs i el seu origen s'adrecen a la discussió. 


\section{Resultats}

\subsection{Castellà i gallec}

Els resultats d'aquesta secció es basen en les redaccions de 5 participants residents a Galícia (1 redacció per participant) i en 12 redaccions de 6 participants de parla castellana a Catalunya (2 per participant). Els exemples de la mostra que pertanyen a participants d'L1 gallec s'indiquen amb (gall.).

\section{Temps}

La taula 2 recull les diferències en l'ús dels temps verbals i sembla que no hi hagi cap tendència clara que les unifiqui. El futur de probabilitat és un error recurrent entre parlants d'espanyol que aprenen català, possiblement perquè el castellà el permet. Tanmateix, el segon error podria raure en la confusió entre els temps dintre del mode subjuntiu.

Taula 2. Característiques temporals verbals de la IL castellano-galaica

\begin{tabular}{|l|l|l|l|}
\hline Contrast & Exemple & Català & Participant \\
\hline Futur de probabilitat & $\begin{array}{l}\text { suposo que estaràs molt } \\
\text { entretinguda (gall. })\end{array}$ & $\underline{\text { deus estar }}$ & JC \\
\hline Passat-Present & $\begin{array}{l}\text { m'agrada molt més anar } \\
\text { a treballar i que algú em } \\
\text { fes la feina de casa }\end{array}$ & $\underline{\text { faci }}$ & RA \\
\hline Present-Passat & el clima era humit & $\underline{\text { és }}$ & AM \\
\hline
\end{tabular}

\section{Aspecte}

La taula 3 reflecteix que la distinció que causa més diferències és la de perfet-perfectiu (11 casos) que, com descriu la Gramàtica de la llengua catalana (2016), reflecteix una diferència "no tan nítida" i que "no resulta rellevant" en alguns casos. Tanmateix, la distinció perfectiuperfet (3) és menys problemàtica. La diferència quantitativa entre els errors que trobem en la distinció perfet-perfectiu (11) i perfectiu-perfet (3) podria deure's a diversos motius com, per exemple, que aquests estudiants haguessin après el perfet primer i, per tant, l'haguessin generalitzat, o bé que es produeixi una seqüència de desenvolupament interna segons la qual se sobregeneralitza el perfet temporalment. Com suggereix un avaluador, aquesta qüestió també podria tenir l'arrel en el fet que algunes varietats castellanes usen el passat simple, fui, per referir-se a accions passades, encara que hagin succeït el mateix dia en què s'està parlant. Sembla que els estudiants combinin la representació mental del perfet i del perfectiu quan visualitzen el perfet simple castellà. En la resta de casos la tendència és a sobregeneralitzar el perfet, i el perfectiu en menor mesura, en contextos que demanen l'imperfectiu.

Taula 3. Característiques aspectuals de la IL castellano-galaica

\begin{tabular}{|l|l|l|l|}
\hline Contrast & Exemple & Català & Participant \\
\hline Perfectiu-Perfet & $\begin{array}{l}\text { sempre vaig ser de la idea que } \\
\text { les llengües obrien portes a la } \\
\text { comunicació (gall.) }\end{array}$ & $\underline{\text { he estat }}$ & BR \\
Avui em vaig llevar (gall. \\
$\begin{array}{l}\text { Sempre vaig conèixer molta } \\
\text { gent }\end{array}$ & $\underline{\underline{\text { m'he llevat }}}$ & RV conegut \\
RT
\end{tabular}




\begin{tabular}{|c|c|c|c|}
\hline $\begin{array}{l}\text { Perfet-Perfectiu } \\
\text { (11) }\end{array}$ & $\begin{array}{l}\text { el dijous passat he anat }[\ldots] \text { i he } \\
\text { vist }\end{array}$ & $\begin{array}{l}\text { vaig anar, } \\
\text { vaig veure }\end{array}$ & $\mathrm{BR}$ \\
\hline & $\begin{array}{l}\text { el viatge que he fet l'estiu passat } \\
\text { [...] Ha estat increible }\end{array}$ & $\begin{array}{l}\text { vaig fer, va } \\
\underline{\text { ser }}\end{array}$ & MG \\
\hline & $\begin{array}{l}\text { Hem anat per visitar els meus } \\
\text { pares }\end{array}$ & $\underline{\text { Hi vam anar }}$ & $\mathrm{CM}$ \\
\hline & La setmana passada han vingut & van venir & $\mathrm{CF}$ \\
\hline & $\begin{array}{l}\text { els dos dies havíem menjat al } \\
\text { bufet }\end{array}$ & vam menjar & SF \\
\hline $\begin{array}{l}\text { Perfet- } \\
\text { Imperfectiu }\end{array}$ & $\begin{array}{l}\text { com que [en aquell moment, } \\
\text { continuïtat estativa] havia } \\
\text { portat la documentació [me la } \\
\text { van robar] (gall.) }\end{array}$ & portava & $\mathrm{RV}$ \\
\hline $\begin{array}{l}\text { Perfectiu- } \\
\text { Imperfectiu }\end{array}$ & $\begin{array}{l}\text { Espero que el vostre estiu va ser } \\
\text { més divertit (gall.) }\end{array}$ & $\underline{\text { fos }}$ & $\mathrm{RV}$ \\
\hline
\end{tabular}

\section{Mode}

La taula 4 recull les diferències amb relació al mode. Totes les ocurrències reflecteixen la sobregeneralització de l'indicatiu quan caldria utilitzar el subjuntiu (4 casos). Com que el subjuntiu també existeix en castellà, és poc probable que es degui a la incapacitat dels estudiants de discernir les diferències entre els modes. A més a més, si hi hagués transferència de la llengua tipològicament més semblant, no observaríem problemes d'ús (contra el model de preeminència tipològica). Per tant, una explicació més versemblant seria que els estudiants encara no haguessin assolit un estadi de desenvolupament que els permeti d'usar el subjuntiu, a favor de la teoria de la processabilitat.

Taula 4. Característiques modals de la IL castellano-galaica

\begin{tabular}{|l|l|l|}
\hline Exemple & Català & Participant \\
\hline $\begin{array}{l}\text { Espero que el vostre estiu va ser } \\
\text { més divertit } \text { (gall.) }\end{array}$ & $\underline{\text { fos }}$ & RV \\
\hline Era abans que ha nascut & $\underline{\text { hagués nascut }}$ & JT \\
\hline $\begin{array}{l}\text { És molt estrany que la gent parla } \\
\text { poc anglès }\end{array}$ & parli & MG \\
\hline no crec que m'agrada & $\underline{\text { magradés }}$ & AM \\
\hline
\end{tabular}

\section{Verbs buits}

La taula 5 recull les característiques dels verbs buits. Les diferències rauen principalment en la presència de estar amb valor locatiu en lloc de ser (5 casos) i en l'omissió del pronom hi en el verb haver-hi (4 casos). Ambdues característiques es poden explicar mitjançant la transferència negativa des del castellà, que usa estar locativament i no requereix cap pronom per haver en el sentit de haver-hi. 
Taula 5. Verbs buits en la IL castellano-galaica

\begin{tabular}{|c|c|c|c|}
\hline Tret & Exemple & Català & Participant \\
\hline $\begin{array}{l}\text { estar amb valor } \\
\text { locatiu }\end{array}$ & $\begin{array}{l}\text { quan estava a la platja } \\
\text { [moment concret] (gall.) } \\
\text { magradaria moltíssim } \\
\text { que estiguessis també } \\
\text { vaig estar [allà] amb el } \\
\text { meu xicot quatre dies } \\
\text { ell no podrà estar }\end{array}$ & $\begin{array}{l}\underline{\text { era }} \\
\underline{\text { hi fossis }} \\
\underline{\text { vaig ser-hi }} \\
\underline{\text { ser-hi }}\end{array}$ & CR \\
\hline $\begin{array}{l}\text { Sobregeneralització } \\
\text { de l'ús de estar }\end{array}$ & $\begin{array}{l}\text { he estat un dia complet } \\
\text { (al Louvre) } \\
\text { saps qui estava allà } \\
\text { D’una banda està genial } \\
\text { (gall.) }\end{array}$ & $\begin{array}{l}\underline{\text { hi vaig ser }} \\
\underline{\text { hi havia }} \\
\underline{\text { és }}\end{array}$ & $\begin{array}{l}\text { MG } \\
\text { CM } \\
\text { CS }\end{array}$ \\
\hline $\begin{array}{l}\text { Omissió del pronom } \\
\text { hi en haver-hi }\end{array}$ & $\begin{array}{l}\underline{\text { havia molts turistes }} \\
\text { (gall.) } \\
\text { més lluny havia un castell } \\
\text { vam passejar per una fira } \\
\text { artesanal que havia } \\
\text { que hagi una casa rural a } \\
\text { la muntanya }\end{array}$ & $\begin{array}{l}\underline{\text { hi havia }} \\
\text { hi havia } \\
\underline{\text { hi havia }}\end{array}$ & $\begin{array}{l}\text { RV } \\
\text { AM } \\
\text { RV }\end{array}$ \\
\hline ser en lloc d'estar & és molt net & està & MG \\
\hline
\end{tabular}

\section{Règim}

A la mostra, com recull la taula 6, la primera diferència amb el català és la generalització de dubtar de, sense tenir en compte que cal que vagi seguit d'un substantiu i que tenir dubtes regeix la preposició sobre. La segona mostra no té una explicació clara; aparentment, l'estudiant interpreta la frase com a passiva i vol introduir un complement agent o bé diferenciar l'expressió del castellà, perquè en aquest cas el verb regeix la mateixa preposició en ambdues llengües.

Taula 6. Règim de la IL castellano-galaica

\begin{tabular}{|l|l|l|}
\hline Exemple & Català & Participant \\
\hline$\underline{\text { tenia dubtes de canviar de feina }}$ & $\underline{\text { tinc dubtes sobre }}$ & RA \\
\hline $\begin{array}{l}\text { tu estàs animada per fer aquest } \\
\text { viatge }\end{array}$ & animada a & AF \\
\hline
\end{tabular}

\section{Perífrasis verbals}

La IL dels estudiants d'aquesta mostra no es caracteritza per l'assimilació incorrecta de l'ús de les perífrasis verbals. Tan sols hi ha un error entre els participants gallecs, en què l'estudiant ha utilitzat la perífrasi d'obligació castellana tenir que (RV): "com tinc que anar" en lloc de "com que he d'anar". Més enllà d'aquest exemple idiosincràtic, l'ús de les perífrasis en la IL no es diferencia de la del català. 


\subsection{Italià}

Els resultats d'aquesta secció es basen en les redaccions de 6 participants residents a Itàlia (1 redacció per participant) i 2 redaccions d'1 participant italià resident a Catalunya. Els estudiants d'aquesta mostra eren més avançats, B1 alt-B2.

\section{Temps}

Tan sols hi ha un cas en què l'ús del temps verbal es diferencia del català: la distinció entre el present i el passat imperfet en el mode subjuntiu, si (jo) no ${ }^{\star}$ tinguis que en lloc de tingués (IB). La distinció entre els dos temps de subjuntiu també existeix en italià, així que la dificultat podria deure's a un error ortogràfic o bé a una seqüència de desenvolupament segons la qual el present es desenvolupa abans del passat en el subjuntiu després de ser après en l'indicatiu. Aquest també és l'únic cas de concordança, ja que s'hi ha utilitzat la segona persona del singular en lloc de la primera.

Aspecte

Com mostra la taula 7, en general, la IL dels italòfons no es diferencia significativament del català pel que fa a l'aspecte. Com en la IL castellano-galaica, la distinció entre perfet-perfectiu (2) és la més problemàtica, tot i que el nombre de casos és molt més baix. L'italià diferencia entre el perfectiu, l'imperfectiu i el duratiu, per tant, és lògic que les dificultats sorgeixin en la distinció entre perfet i perfectiu. Tot i així, quantitativament, els problemes amb l'aspecte són escassos.

Taula 7. Característiques aspectuals verbals de la IL italiana

\begin{tabular}{|l|l|l|l|}
\hline Contrast & Exemple & Català & Participant \\
\hline $\begin{array}{l}\text { Imperfectiu- } \\
\text { Perfectiu }\end{array}$ & la mar era una decepció & va ser & MA \\
\hline Perfet-Perfectiu & al final tot ha anat bé & va anar & IR \\
\hline Perfectiu-Perfet & $\begin{array}{l}\text { sempre vaig ser el meu } \\
\text { somni }\end{array}$ & $\underline{\text { ha estat }}$ & SS \\
\hline
\end{tabular}

\section{Verbs buits}

La taula 8 mostra que la majoria de diferències ( 4 de 5) provenen del mateix participant, l'RL. L'italià atribueix el valor locatiu a ser 'essere', com el català, mentre que per parlar de qualitats o condicions (tant si són perennes com temporals) usa estar, 'stare'. Així mentre que la diferència és atribuïble a la transferència negativa des de l'italià, l'ús locatiu de estar (exemples 1 i 2) podria derivar-se de la transferència negativa del castellà, ja que molts estudiants també el parlen; o bé a la interpretació que els estudiants fan de la sobresimplificació que a vegades s'usa a l'aula. Concretament em refereixo a etiquetar estar com a quelcom temporal i ser com a permanent. Aquesta divisió pot dur l'estudiant a interpretar "raure en un lloc" com una situació efímera perquè ens movem i canviem de lloc, i atribuir la qualitat locativa a estar.

Un altre tret present és l'ús de estar per haver-hi. Havent observat una confusió en la distribució general de ser i estar, i sabent que en italià s'utilitza el verb pronominal esserci per haver-hi (Ci sono fiore / Hi ha flors), és probable que el parlant d'L1 italiana projecti sobre la IL construccions com la quarta de la taula 8. La cinquena qüestió podria ser causada per la TN, ja que l'italià usa el verb essere com a auxiliar en la construcció de passat dels verbs reflexius 
Taula 8. Verbs buits en la IL italiana

\begin{tabular}{|l|l|l|l|}
\hline Tret & Exemple & Català & Participant \\
\hline $\begin{array}{l}\text { estar amb valor } \\
\text { locatiu }\end{array}$ & $\begin{array}{l}\text { ara estic en la biblioteca } \\
\text { al final estava al mar }\end{array}$ & $\begin{array}{l}\underline{\text { soc }} \\
\text { era }\end{array}$ & MA \\
\hline ser per a estats & jo $\underline{\text { soc } \text { entusiasta }}$ & $\begin{array}{l}\underline{\text { estic }} \\
\text { entusiasmat/da }\end{array}$ & SS \\
\hline estar per haver-hi & $\underline{\text { estava } \text { tant gent }}$ & $\underline{\text { hi havia }}$ & MA \\
\hline Auxiliaritat & em $\underline{\text { soc } \text { divertit }}$ & $\underline{\text { he }}$ & \\
\hline
\end{tabular}

\section{Perifrasis verbals}

La taula 9 recull els dos únics casos en què s'han trobat diferències pel que fa al règim verbal. En aquest cas, sembla que els estudiants transfereixin la perífrasi d'obligació tenir que del castellà, la primera llengua romànica no nativa apresa per la majoria. La construcció de la llengua italiana es correspon a devere + infinitiu, que tampoc reflecteix els trets de la IL.

Taula 9. Perífrasis verbals la IL italiana

\begin{tabular}{|l|l|l|}
\hline Exemple & Català & Participant \\
\hline no tinguis que & $\underline{\text { hagués de }}$ & IB \\
\hline tinc que trobar & $\underline{\text { he de }}$ & SS \\
\hline
\end{tabular}

\subsection{Francès}

Els resultats d'aquesta secció es basen en les redaccions obtingudes de 13 participants (1 redacció per persona). Tots els alumnes residien a França.

\section{Temps}

Les dades presentades a la taula 10 suggereixen que la IL dels francesos es caracteritza per la sobregeneralització del present d'indicatiu i de subjuntiu quan hi ha un buit en el seu coneixement. D'altra banda, BC, DL i AC compensen la falta de coneixement del condicional amb el present, mentre que $\mathrm{AC}$ i BF podrien no haver après l'imperfet de subjuntiu i utilitzar el present del mode per ocupar-ne el lloc. Mentre que aquests participants sembla que no hagin adquirit les característiques temporals dels verbs, LM mostra variabilitat i utilitza el futur correctament a vegades.

Taula 10. Característiques temporals verbals de la IL francesa

\begin{tabular}{|l|l|l|l|}
\hline Contrast & Exemple & Català & Participant \\
\hline $\begin{array}{l}\text { (present) } \\
\text { Imminència-Futur }\end{array}$ & $\underline{\text { van a posar una música }}$ & $\underline{\text { posaran }}$ & \\
\hline Present-Condicional & $\begin{array}{l}\text { li agrada tenir nens amb mi } \\
\text { cal que tingui }\end{array}$ & $\underline{\text { agradaria }}$ & BC \\
& $\begin{array}{l}\text { caldria, } \underline{\text { tingués }} \\
\text { també el noi deu ser }\end{array}$ & DL \\
\hline Present-Futur & no $\underline{\text { hou agria de }}$ & AC \\
\hline Present-Passat & voldria que $\underline{\text { sigui de fusta }}$ & $\underline{\underline{\text { ens estimarà }}}$ & LM \\
\hline & que la façana sigués & $\underline{\text { fos }}$ & \\
\hline
\end{tabular}




\section{Aspecte}

Totes les diferències recollides a la taula 11 provenen del participant $\mathrm{MH}$. En general, la seva IL es correspon als usos de la llengua catalana pel que fa als imperfectius i perfectius, però no hi ha cap indicació que usi el perfet correctament, la qual cosa suggereix representacions aspectuals lleugerament inestables.

Taula 11. Característiques aspectuals verbals de la IL francesa

\begin{tabular}{|l|l|l|l|}
\hline Contrast & Exemple & Català & Participant \\
\hline $\begin{array}{l}\text { Imperfectiu- } \\
\text { Perfectiu }\end{array}$ & $\underline{\text { Érem al càmping }}$ & vam estar-nos & \\
\cline { 1 - 2 } Perfet-perfectiu & com s'ha mort el forner & $\underline{\text { va morir }}$ & MH \\
\hline
\end{tabular}

Mode

Com la IL castellano-galaica, la francesa tendeix a sobregeneralitzar l'indicatiu en casos que requereixen el subjuntiu (11), dels quals 5 es presenten a la taula 12 . Tenint en compte que el francès també té el subjuntiu i que funciona de manera relativament similar al català, la transferència lingüística no en sembla la causa, sinó més aviat la manifestació d'un estadi natural en l'aprenentatge del català.

Taula 12. Característiques modals de la IL francesa

\begin{tabular}{|l|l|l|}
\hline Exemple & Català & Participant \\
\hline no sóc una noia que lliga & $\underline{\text { ligui }}$ & LM \\
\hline pot ser que traballa o que estudia & $\underline{\text { treballi, estudii }}$ & AC \\
\hline com ho semblen pensar & $\underline{\text { sembla que ho pensin }}$ & ER \\
\hline demanem que fa & $\underline{\text { faci }}$ & MM \\
\hline I si és possible & $\underline{\text { fos }}$ & DL \\
\hline
\end{tabular}

\section{Verbs buits}

La taula 13 presenta les diferències amb relació als verbs buits. Hi ha una sobregeneralització de l'ús de ser en contextos en què caldria utilitzar estar. Aquest patró trenca amb la tendència d'emprar estar amb valor locatiu observada en seccions anteriors. L'origen del fenomen sembla raure en la combinació de ser i estar en el francès être. En la IL francesa, ser podria ser l'opció per defecte que ompliria el lloc de ser i estar.

L'altra característica que mereix atenció és l'ús de haver-hi. La LM afegeix hi quan apareix ha com a auxiliar, no tan sols com a pronom en el verb haver-hi; tot i que, per contra, BC omet completament haver. Aparentment, BC fluctua en la correcció, ja que en una altra ocasió utilitza haver-hi adequadament, mentre que LM fa el mateix error sistemàticament.

Taula 13. Verbs buits en la IL francesa

\begin{tabular}{|l|l|l|} 
Exemple & Català & Participant \\
\hline la persona pot ser espantat & $\underline{\text { estar }}$ & BC \\
quan som enamorats & $\underline{\text { estem }}$ & LM \\
encara que sóc trista & $\underline{\text { estigui }}$ & AC \\
$\underline{\text { érem al càmping }}$ & $\underline{\text { estar-nos }}$ & MH \\
que sigui en un barri & $\underline{\text { estigui }}$ & DL \\
\hline
\end{tabular}




\begin{tabular}{|l|l|l|l|}
\hline haver-hi & $\underline{\text { hi otras persónas }}$ & $\underline{\text { hi ha }}$ & BC \\
\hline haver-hi (sobreús) & $\begin{array}{l}\text { no hi ha de buscar } \\
\text { hi ha de ser } \\
\text { no hi ha de oblidar }\end{array}$ & $\underline{\underline{\text { s'ha }}}$ & LM \\
s'ha & $\underline{\text { s'ha }}$ & \\
\hline Auxiliaritat & quan dec pagar & $\underline{\text { he de }}$ & AC \\
\hline
\end{tabular}

\section{Règim}

Com es palesa a la taula 14 , no hi ha cap patró clar en els errors pel que fa al règim i els casos són pocs. La TN podria explicar el primer i el tercer error; tanmateix, no explica el segon, en què les estructures també són paral-leles.

Taula 14. Règim de la IL francesa

\begin{tabular}{|l|l|l|}
\hline Exemple & Català & Participant \\
\hline (1) pensar a & $\underline{\text { en }}$ & GO \\
\hline (2) pel que fa l'amor & $\underline{\text { fa a l'amor }}$ & QC \\
\hline (3) que toqués el sol & que hi toqués & AT \\
\hline
\end{tabular}

\section{Perifrasis verbals}

La taula 15 mostra que totes les característiques provenen del mateix estudiant, que no utilitza la perífrasi d'obligació haver de catalana. En el primer cas, empra la perífrasi castellana catalanitzada tenir que; en el segon, utilitza una perífrasi de probabilitat, que podria originarse en la TN del francès, devrait être.

Taula 15. Perífrasis verbals la IL francesa

\begin{tabular}{|l|l|l|}
\hline Exemple & Català & Participant \\
\hline però tenim que & hem de & AC \\
\hline també el noi deu ser & $\underline{\text { hauria de }}$ & \\
\hline
\end{tabular}

\section{Concordança}

La taula 16 recull les diferències pel que fa a la concordança verbal. La IL francesa és l'única IL romànica amb exemples d'errors de concordança. Com la interllengua anglesa, les diferències apareixen en verbs psicològics de la classe C, del tipus agradar. Aquests verbs són estatius i denoten estats mentals en què el complement indirecte rep el paper temàtic d'experimentador i el subjecte és el tema, com passa amb el verb agradar. En aquests casos l'estudiant confon el règim i atribueix al subjecte el paper de complement, i al complement el paper de subjecte. Els estudiants podrien identificar-se com a subjecte perquè ells són qui parlen, sense adonarse que són l'experimentador i el que perceben com a objecte és la causa de l'acció i, per tant, el subjecte; per contra del francès, en què el subjecte és l'experimentador, la qual cosa indica possible transferència negativa del francès. 
Taula 16. Concordança en la IL francesa

\begin{tabular}{|c|c|c|c|}
\hline Fenomen & Exemple & Català & Participant \\
\hline Nombre & L'amor, com la seducció, són & és & $\mathrm{BC}$ \\
\hline Subjecte-Objecte & $\begin{array}{l}\text { em ofereix (els homes) } \\
\text { (els homes) } \underline{\text { em diu }} \\
\text { com ho semblen pensar } \\
\underline{\text { m'agrada més les cerveses }}\end{array}$ & $\begin{array}{l}\text { m'ofereixen } \\
\text { em diuen } \\
\text { sembla que ho pensin } \\
\underline{\text { m'agraden }}\end{array}$ & GO \\
\hline Subjecte & no saps si seria & $\underline{\text { sé }}$ & $\mathrm{AC}$ \\
\hline
\end{tabular}

\subsection{Anglès}

Els resultats d'aquesta secció es basen en les redaccions de 6 participants del Regne Unit i 5 dels Estats Units. Cada participant escriví 1 redacció.

\section{Temps}

Malgrat que tan sols observem 1 cas en què el temps és problemàtic, és interessant perquè l'arrel de l'error és ben clara, la TN de l'anglès: ${ }^{*}$ s'està quedant a casa meva en lloc de s'està, "he is staying". L'estudiant extrapola les implicacions duratives de l'expressió anglesa directament al quedar-se català, que no en permet l'ús amb la construcció progressiva.

\section{Aspecte}

Cal destacar que la majoria de diferències rauen en la sobregeneralització de l'imperfectiu ( 5 casos) en contextos que demanen el perfectiu o el perfet. Com es mostra a la taula 17, tan sols en 3 ocasions trobem el problema contrari en què s'usa un verb en forma perfectiva en lloc de la imperfectiva. En general, no sembla que puguem atribuir les diferències a l'L1, ja que l'anglès diferencia entre perfectiu, imperfectiu i progressiu; tot i que la distinció a nivell morfològic és diferent. Una hipòtesi plausible seria que els estudiants es troben en els estadis inicials de formació de les representacions lingüístiques aspectuals dels verbs catalans, cosa que provoca la variabilitat en l'ús de les formes que observem.

El contrast que caracteritza la resta de dissimilituds és la de perfectiu-perfet (4 casos). Com ja s'ha explicat, aquesta distinció no existeix en les L1 de la mostra com existeix en català $\mathrm{i}$ reflecteix un matís més subtil que el de l'imperfectiu-perfectiu i imperfectiu-perfet.

Taula 17. Característiques aspectuals verbals de la IL anglesa

\begin{tabular}{|l|l|l|l|}
\hline Contrast & Exemple & Català & Participant \\
\hline $\begin{array}{l}\text { Imperfectiu- } \\
\text { Perfectiu }\end{array}$ & $\begin{array}{l}\text { després d'una segona } \\
\text { investigació podia } \\
\text { observar }\end{array}$ & vaig poder \\
$\begin{array}{l}\text { quan la porta ha obrit } \\
\text { completament podia } \\
\text { veure tres gossos }\end{array}$ & $\begin{array}{l}\text { va obrir, } \\
\text { em vaig mirar i } \\
\text { començavan }\end{array}$ & $\underline{\text { van començar }}$ \\
$\begin{array}{l}\text { Mai sabia per què tenia } \\
\text { l'Eddy }\end{array}$ & $\underline{\text { havia sabut }}$ & NF \\
\hline
\end{tabular}




\begin{tabular}{|c|c|c|c|}
\hline Imperfectiu-Perfet & $\begin{array}{l}\text { estava agraïda per } \\
\text { l'oportunitat de treballar } \\
\text { amb ella [ja he deixat de } \\
\text { treballar-hi] }\end{array}$ & $\frac{\text { d'haver }}{\text { treballat }}$ & LD \\
\hline $\begin{array}{l}\text { Perfectiu- } \\
\text { Imperfectiu }\end{array}$ & $\begin{array}{l}\begin{array}{l}\text { L'aigua era càlida i ella va } \\
\text { nedar cada matí }\end{array} \\
\underline{\text { va ser enorme }} \\
\text { Fins i tot ara la meva } \\
\text { mare em va dir }\end{array}$ & $\begin{array}{l}\text { nedava } \\
\underline{\text { era }} \\
\underline{\text { diu }}\end{array}$ & $\begin{array}{l}\text { JB } \\
\text { NF }\end{array}$ \\
\hline Perfectiu-Perfet & $\begin{array}{l}\text { avui vaig anar a prendre } \\
\text { [avui] també vaig anar } \\
\text { a... } \\
\text { voldria explicar-te què } \\
\text { vaig passar } \\
\text { [fa un moment] em vaig } \\
\text { oblidar de... }\end{array}$ & $\begin{array}{l}\text { he anat } \\
\text { he anat } \\
\text { m'ha passat } \\
\text { he oblidat }\end{array}$ & EA \\
\hline
\end{tabular}

\section{Mode}

Com en les altres interllengües i com es reflecteix a la taula 18, les dificultats amb relació al mode rauen en la sobregeneralització de l'indicatiu en contextos on es necessita el subjuntiu. En el cas de l'anglès, no es pot determinar amb claredat si l'error rau en l'absència del subjuntiu en la quotidianitat de l'anglès o bé l'estadi de desenvolupament lingüístic. Tanmateix, tenint en compte que les altres ILs que comparteixen aquesta característica es componen de parlants d'L1s amb subjuntiu, la segona explicació s'afigura més probable.

Taula 18. Característiques modals de la IL anglesa

\begin{tabular}{|l|l|l|}
\hline Exemple & Català & Participant \\
\hline amb el qual poden gaudir & puguin & MA \\
\hline $\begin{array}{l}\text { si no hi han suficients persónes } \\
\text { que parlen }\end{array}$ & parlin & LF \\
\hline No hi havia res que podía fer! & pogués & AH \\
\hline
\end{tabular}

\section{Verbs buits}

La taula 19 reflecteix que la IL dels anglòfons es caracteritza per l'ús locatiu del verb estar en detriment del ser català. L'anglès no distingeix entre ser i estar, sinó que utilitza un únic verb, to be, en ambdós contextos. És possible que el parlant utilitzi estar per a expressions locatives per com s'ensenya el català o el principi one-to-one (vegeu seccions anteriors) o per TN del castellà. 
Taula 19. Verbs buits en la IL anglesa

\begin{tabular}{|l|l|l|l|}
\hline Tret & Exemple & Català & Participant \\
\hline estar locatiu & que no estava a la meva feina & $\underline{\text { era }}$ & LD \\
& que havia d'estar & $\underline{\text { ser }}$ & \\
& $\underline{\text { està aquí per fer }}$ & $\underline{\text { és }}$ & HJ \\
& jo estava al capdavall del carrer & $\underline{\text { era }}$ & JB \\
\hline
\end{tabular}

\section{Règim}

El règim no és deduïble en la majoria de casos, ja que no és una combinació de mots amb significat propi. La taula 20 reflecteix que la IL dels anglòfons és una de les que més es caracteritzen per un ús diferenciat del règim verbal. En la meitat dels casos (4) es pot explicar l'error a través de TN de tell about i go for, en l'ordre de la taula 20. En la resta de la mostra els estudiants han intransitivitzat el verb (2 casos) o substituït la preposició (1 cas).

Taula 20. Règim en la IL anglesa

\begin{tabular}{|c|c|c|c|}
\hline Tret & Exemple & Català & Participant \\
\hline $\mathrm{TN}$ & $\begin{array}{l}\text { li he explicat sobre la meva } \\
\text { experiència } \\
\text { no t'he dit sobre el meu viatge } \\
\text { em vaig oblidar de explicar sobre la } \\
\text { meva viatge } \\
\text { Anava [...] per prendre un cafè }\end{array}$ & $\begin{array}{l}\text { explicat la } \\
\underline{\text { explicat el }} \\
\underline{\text { d'explicar-te el }} \\
\underline{\text { aneu }} \\
\text { ana }[. . .] \text { a }\end{array}$ & $\begin{array}{l}\mathrm{LD} \\
\mathrm{CO}\end{array}$ \\
\hline Transitivització & $\begin{array}{l}\text { com s'està quedant casa meva } \\
\text { senfronta molts obstacles }\end{array}$ & $\begin{array}{l}\text { que s'està } \\
\text { quedant a casa } \\
\text { s'enfronta a }\end{array}$ & $\begin{array}{l}\mathrm{HJ} \\
\mathrm{MA}\end{array}$ \\
\hline Substitució & en vaig tirar pel dinosaure & tirar al & JB \\
\hline
\end{tabular}

\section{Perífrasis verbals}

La taula 21 recull les diferències en l'ús de les perífrasis verbals. En la mostra, no sembla que la IL dels angloparlants es caracteritzi per dificultats significatives amb l'ús de les perífrasis verbals, perquè tan sols hi apareixen dues diferències respecte al català que, a més a més, són diferents entre si. Tanmateix, com en altres ILs, la perífrasi d'obligació haver de també se substitueix per tenir que.

Taula 21. Perífrasis verbals de la IL anglesa

\begin{tabular}{|l|l|l|}
\hline Exemple & Català & Participant \\
\hline que tenia que ser allà & $\underline{\text { havia de }}$ & LD \\
\hline un dinosaure va córrer pel carrer & $\begin{array}{l}\text { va començar a } \\
\text { córrer }\end{array}$ & JB \\
\hline
\end{tabular}




\section{Concordança}

La taula 22 mostra que la IL dels anglòfons es caracteritza per una barreja entre diferències purament de concordança ( 4 casos), probablement a causa de la poca especificació morfològica per marcar la persona en el sistema anglès, i errors ocasionats per verbs psicològics de la classe C (4), ja descrits a l'apartat anàleg sobre la IL francesa.

Taula 22. Concordança en la IL anglesa

\begin{tabular}{|l|l|l|l|}
\hline Tret & Exemple & Català & Participant \\
\hline $\begin{array}{l}\text { Manca de } \\
\text { concordança }\end{array}$ & $\begin{array}{l}\text { [jo] em va arribar a temps } \\
\text { [jo] ha intentat menjar } \\
\text { era les restes d'un avió } \\
\text { obstacles que han de vèncer [el català] }\end{array}$ & $\begin{array}{l}\underline{\text { vaig arribar }} \\
\text { he intentat }\end{array}$ & CO \\
ER de \\
$\begin{array}{l}\text { Complement- } \\
\text { Subjecte }\end{array}$ & $\begin{array}{l}\text { sé que t’agradaries molt al ciutat } \\
\text { voldria explicar-te què vaig passar }\end{array}$ & $\begin{array}{l}\text { t'agradaria } \\
\text { m'ha passat }\end{array}$ & AH \\
\hline
\end{tabular}

\section{Discussió}

\subsection{La transferència lingüística en la IL}

La primera pregunta investiga l'origen de les diferències entre el sistema verbal català i el de la IL dels parlants de la mostra. La taula 23 presenta un resum de les característiques de la IL que podrien explicar-se a través de la transferència lingüística; com s'hi palesa, són poques les qüestions que la transferència pot justificar. Per exemple, en la interllengua dels castellanoparlants un participant utilitza el present d'indicatiu, "no crec que m'agrada ${ }^{*}$, en lloc del subjuntiu, "m'agradés", malgrat que el subjuntiu també existeix en castellà. Tan sols alguns dels errors podrien explicar-se així, però els resultats varien en funció de la llengua i la característica. En la mostra castellano-galaica, els errors en 2-3 propietats poden ser causats per transferència; en la italiana, 2-3; en la francesa, 2-5, i en l'anglesa, 2-7. Els intervals reflecteixen que algunes qüestions podrien deure's a la transferència lingüística, però també a altres fenòmens. Per exemple, en el cas de l'ús de estar amb valor locatiu (present en totes les ILs excepte la francesa), la transferència negativa des de l'L1 o l'L2 podria explicar la característica; tanmateix, i especialment si tenim en compte la variabilitat entre ser i estar en la IL francesa, hom també pot advocar per una seqüència de desenvolupament en què les representacions de ser i estar serien inestables. Tenint en compte que els perfils dels estudiants són heterogenis, les LEs que s'han tingut en compte com a candidates per transferència lingüística han estat les L1s, el castellà, i l'anglès; de les quals tan sols el castellà i les L1s han estat productives.

Taula 23. Resum de les característiques que mostren transferència

\begin{tabular}{|c|c|c|c|c|}
\hline Característica & L1 & & & \\
\hline V & Castellà/gallec & Italià & Francès & Anglès \\
\hline Temps & $\mathrm{X}$ & $\mathrm{X}$ & $\mathrm{X}$ & $\sim$ \\
\hline Aspecte & $\sim$ & $\sim$ & $\sim$ & $\sim$ \\
\hline Mode & $\mathrm{X}$ & $\mathrm{X}$ & $\mathrm{X}$ & $\sim$ \\
\hline Verbs buits & $\checkmark$ & $\checkmark$ L1/L2 & $\sim$ & $\sim \mathrm{L} 2$ \\
\hline Règim & $\mathrm{X}$ & $\mathrm{X}$ & $\sim$ & $\sim$ \\
\hline Perífrasis verbals & $\checkmark$ & $\checkmark \mathrm{L} 2$ & $\checkmark \mathrm{L} 2$ & $\checkmark \mathrm{L} 2$ \\
\hline Concordança & $\mathrm{X}$ & $\mathrm{X}$ & $\checkmark$ & $\checkmark$ \\
\hline
\end{tabular}

Nota. ' $\mathrm{X}$ ' indica manca de transferència, ' $\checkmark$ ' indica transferència, ' $\sim$ ' indica resultats inconclusius, 'L2' indica que la transferència vindria de l'L2 en lloc de l'L1. 
Contra la primera i la segona hipòtesi, els errors d'aquesta mostra no sembla que es puguin atribuir a la transferència sencera del sistema lingüístic més tipològicament similar (contra l'MPT) ni a la transferència de característiques concretes percebudes com a tipològicament més similars (contra l'MPL). L'observació dels verbs buits revela que les ILs tendeixen a l'ús de estar amb valor locatiu, una qüestió present també entre nadius i que alguns autors atribueixen a la influència castellana (Solà, 1981). Hi ha diverses possibilitats que podrien justificar la presència de l'error: la sobresimplificació natural de les interllengües, el principi one-to-one (una forma un significat), o l'explicació que a vegades s'usa a les aules (estar és temporal i ser inherent). Les dues últimes explicacions produeixen els mateixos resultats, per tant, no podem discernir quina és més probable. El castellà sembla ser l'origen de l'error perquè usa estar locativament; així l'L1 seria la causa entre els castellanoparlants, o l'L2 entre els anglòfons i italòfons (a favor de l'MPT). Tanmateix, els francòfons segueixen un altre patró.

Per arribar a l'arrel de la qüestió, es podria argumentar que els aprenents d'L1 italiana i anglesa es diferencien perquè (1) basen les seves decisions en l'L2 (el castellà), tot reproduint els processos d'aprenentatge de l'L2 (EL2; Bardel i Falk, 2007); (2) copien el sistema lingüístic que perceben com a més similar (MPT; Rothman, 2011), el castellà; o (3) imiten una característica concreta percebuda com a tipològicament més similar a la LM (MPL; Westergaard et al., 2016). Tanmateix, si les explicacions (1) i (2) fossin correctes, les altres qüestions entre els italòfons i anglòfons també reflectirien transferència des de l'L2, però aquest no és el cas. L'explicació (3) no és plausible perquè l'italià comparteix la propietat locativa del català, per tant, els aprenents haurien de prioritzar la transferència des de l'italià. Aquestes possibilitats també deixen de banda els francòfons, que generalitzen ser per estar en tots els casos. El francès combina els dos verbs en être, que els estudiants de la mostra traduirien per ser, convertint-lo en l'opció per defecte. Per tant, intralingüísticament, la transferència (des de l'L1 o L2) explicaria els errors, a favor de la segona hipòtesi; tanmateix, interlingüísticament, la possibilitat més versemblant és que hi hagi una seqüència de desenvolupament que afecti els estudiants. L'etapa consistiria en inestabilitat i combinació dels verbs ser i estar, i la generalització de l'un o de l'altre la regularia la transferència lingüística (parcialment a favor de l'MPL). Així, doncs, per explicar el fenomen en el conjunt de les ILs, el més plausible és un període d'inestabilitat en l'ús de ser i estar en què la generalització d'un o altre dependria de les llengües apreses prèviament.

D'acord amb la tercera hipòtesi, la TP proporcionaria el marc teòric més adequat per explicar els problemes amb els verbs buits i el mode perquè, malgrat que el subjuntiu existeix en totes les L1s dels participants (excepte l'anglès), tots hi tenen problemes. Així la dificultat no hauria d'atribuir-se a l'L1, com hom corre el risc de fer si només s'analitza la mostra anglesa. Observant la mostra completa, l'explicació més escaient és que els errors reflecteixin un estadi d'aprenentatge comú. Els únics que no cometen errors de mode són els italòfons, que tenen un nivell més alt. La presència de problemes a nivells baixos que es resolen quan la competència millora reforça l'argument a favor de la TP. Com s'ha explicat, quan una característica s'adquireix, hom pot avançar a la següent, en altres paraules, caldria aprendre les propietats que precedeixen el subjuntiu abans de poder emprar-lo correctament. Malgrat que la mostra no és longitudinal, la juxtaposició entre els italòfons, que tenen un nivell més alt, i els altres grups, que el tenen més baix, és prometedora. Especialment tenint en compte Bonilla (2015a) amb relació al castellà, en què el subjuntiu no s'usa correctament fins a nivells avançats, després d'haver adquirit les característiques dels nivells previs.

Una altra qüestió interlingüística que no es resol amb claredat a través de la transferència és l'aspecte, especialment quant al perfet i al perfectiu, i marginalment l'imperfectiu. Malgrat la similitud interlingüística, hi ha diferències qualitatives. Per exemple, la IL castellano-galaica prioritza l'ús del temps de perfet per sobre del perfectiu, mentre que en l'anglesa el patró 
s'inverteix. Cal considerar diverses possibilitats pels errors: (1) manca de prominència i familiaritat, (2) transferència negativa, (3) ordre d'instrucció i (4) la teoria de la processabilitat.

1. Tenint en compte la manca de claredat de la distinció entre el perfet i el perfectiu que avala la Gramàtica catalana (2016), els estudiants potser no noten la diferència entre els dos (Tomlin i Villa, 1994). Goldschneider i DeKeyser (2001) expliquen que la prominència (salience; Ellis, 2016) d'una característica lingüística, així com el grau d'obstacularització a l'hora de comunicar-se, pot dificultar l'aprenentatge d'un tret. En aquest cas, l'estudiant es faria entendre malgrat l'error; així que la manca de prominència podria justificar les diferències aspectuals.

2. Des de la perspectiva de la TN, els resultats són els mateixos que en el primer cas. Si l'error es deriva de la TN, la manca de distinció entre perfet-perfectiu en la majoria de llengües podria conduir els estudiants a percebre ambdós com a "acció completada en el passat". Per tant, l'aprenent utilitzaria els dos temps verbals de manera intercanviable per cobrir un mateix ús.

3. El rol de la instrucció podria haver condicionat els estudiants a prioritzar aquell temps que s'ha emfatitzat o treballat més recentment a l'aula. Malauradament, la manca d'informació fa que aquesta possibilitat sigui purament especulativa.

4. Segons la teoria de la processabilitat (Pienemann, 1998), els errors reflecteixen una seqüència d'aprenentatge. En aquest cas, la representació mental que els estudiants tenen dels aspectes perfectiu i perfet són inestables i variables; un pas previ a la consolidació que els italòfons ja haurien assolit.

Les quatre opcions són plausibles des d'un punt de vista intralingüístic. Tanmateix, des de la perspectiva interlingüística, com en el cas de ser i estar, la teoria més plausible seria la TP, ja que els aprenents d'L1 italiana, que tenen un nivell més alt, diferencien el perfet i el perfectiu correctament. Els errors d'ús de l'imperfet són molt menys comuns i no ens permeten discernir la seqüència de desenvolupament. La poca freqüència es deu als pocs contextos que s'avenien al seu ús. Per tant, la nostra mostra tan sols ens permet presentar conclusions preliminars i especulatives.

\subsection{Les propietats comunes en la IL}

Respecte la segona pregunta sobre l'existència de característiques comunes entre les diverses ILs, podem dir que aquesta mostra sí que presenta trets comuns entre les ILs independentment de l'L1 dels estudiants: l'aspecte, els verbs buits i les perífrasis verbals. La taula 24 evidencia els trets que presenten diferències respecte del català. Les característiques apareixen en totes les ILs de manera similar. Si excloem els italòfons, el temps, el mode i el règim també mostren trets comuns. En la secció anterior s'ha adreçat el mode, concloent que és problemàtic, però que aparentment deixa de ser una qüestió interlingüística quan el nivell dels participants millora. Així, doncs, el fet que alguns trets no semblin ser comuns podria deure's a la diferència de nivell i a la manca d'homogeneïtat dels grups. Si aquest fos el cas, això proporcionaria més suport per a la TP. L'aspecte i els verbs buits ja s'han discutit amb detall a la secció anterior; per tant, aquí tan sols adreço el temps, el règim i les perífrasis verbals.

Taula 24. Resum de les diferències respecte al català comunes a totes les ILs

\begin{tabular}{|c|c|c|c|c|c|}
\hline Característica & L1 & & & & \\
\hline $\mathrm{V}$ & Castellà/gallec & Italià & Francès & Anglès & Comú \\
\hline Temps & $\mathrm{X}$ & $\mathrm{X}$ & $\mathrm{X}$ & $\sim$ & $\mathrm{X}$ \\
\hline Aspecte & $\sim$ & $\sim$ & $\sim$ & $\sim$ & $\checkmark$ \\
\hline Mode & $\mathrm{X}$ & $\mathrm{X}$ & $\mathrm{X}$ & $\sim$ & $\mathrm{X}$ \\
\hline
\end{tabular}




\begin{tabular}{|l|l|l|l|l|l|}
\hline Verbs buits & $\checkmark$ & $\checkmark$ L1/L2 & $\sim$ & $\sim$ L2 & $\checkmark$ \\
\hline Règim & X & X & $\sim$ & $\sim$ & X \\
\hline Perífrasis verbals & $\checkmark$ & $\checkmark$ L2 & $\checkmark$ L2 & $\checkmark$ L2 & $\checkmark$ \\
\hline Concordança & X & X & $\checkmark$ & $\checkmark$ & X \\
\hline
\end{tabular}

Nota. 'X' indica o hi havia diferències entre el català i la interllengua catalana dels parlants d'aquesta llengua. ' $\checkmark$ ' indica que sí que hi havia diferències.

Amb relació al temps, tots els grups mostren diferències, excepte l'italià. Tanmateix, no sembla haver-hi sistematicitat en els tipus d'errors entre ILs. L'única tendència és a trobar qüestions de temps amb relació al mode subjuntiu, en què s'usa el present en lloc del passat, però no hi solen haver errors de temps i mode. Les diferències respecte al català són negligibles; hi ha 3 casos en la mostra castellano-gallega, 1 en la italiana, 7 en la francesa i 1 en l'anglesa. D'entre totes les ILs, la dels francesos és l'única que recorre al present per compensar el buit en la representació mental del sistema condicional català.

El règim i les perífrasis verbals són un tipus de col-locació especialment difícil per als aprenents d'una llengua estrangera. Diversos estudis han mostrat que, fins i tot entre aquells que passen per nadius, l'ús és problemàtic en castellà (Grañena i Long, 2013), anglès (Spadaro, 2013) i francès (Bartning i Forsberg Lundell, 2018). Per tant, no és sorprenent que hi hagi diferències entre el règim del català i el de les ILs; essent els italòfons l'única excepció. En la majoria de casos, l'error rau en la substitució de la preposició regida pel verb per una que es correspon a la de la seva L1 o a la del castellà. Els únics que es desmarquen i presenten un altre tipus d'error sistemàtic són els anglòfons, que intransitivitzen verbs copiant les restriccions de l'L1.

Pel que fa a les perífrasis, tots els grups han mostrat la mateixa qüestió: tenir que en lloc de la perífrasi d'obligació haver de. En trobem un o dos casos per grup (excepte en el cas dels gallego-castellanoparlants, que no presenten l'error). L'explicació més probable és la TN des del castellà, perquè fins i tot italòfons i francòfons usen tenir que, malgrat que les seves L1s no tenen aquesta construcció. Així semblaria que l'L2 (el castellà) seria la causa més probable de la transferència (taula 23) entre tots els grups. L'excepció seria el castellanoparlant que usa tenir que, ja que probablement la seva L2 seria el català o l'anglès. En ambdós casos, la transferència no seria per via de l'L2, sinó l'L1. Altrament, és possible d'argumentar que el castellanisme és tan present en català actual que els estudiants l'han incorporat en el seu repertori arran de l'input que reben. Sorprenentment, les diferències amb relació al règim i perífrasis no són gaires, probablement a causa de la naturalesa escrita de la tasca i l'accés a diccionaris.

\section{Conclusions i possibles línies de recerca}

Respecte la primera pregunta, les diferències entre el sistema verbal català i les ILs dels parlants de la mostra no es poden explicar únicament a través de la transferència lingüística. A vegades la transferència podria justificar alguns errors intralingüísticament, però interlingüísticament sorgeixen patrons similars que no s'expliquen a través de la transferència; per exemple, els verbs buits, en què la teoria de la processabilitat és l'únic marc teòric que pot adreçar els errors de forma intra- i interlingüística. A grans trets, la transferència és un concepte útil i convenient (Sharwood-Smith, 2020) intralingüísticament per descriure alguns dels fenòmens observats, sobretot a nivells baixos. Tanmateix, interlingüísticament, la TP ofereix una explicació més comprensiva, ja que inclou la possibilitat d'etapes d'inestabilitat en el desenvolupament. La transferència, però, podria jugar un paper de regulació i donar forma a les tendències observades als errors.

Respecte la segona pregunta, la caracterització del sistema verbal de les diverses ILs és possible i les ILs tenen trets comuns que les diferencien del català: l'aspecte, els verbs buits, 
i l'ús incorrecte de la perífrasi d'obligació tenir que. El mode i el règim també reflecteixen dificultats en totes les ILs excepte en la dels italòfons, que constitueixen el grup més petit i avançat. Tanmateix, també hi ha diferències qualitatives entre aquestes característiques, que donen suport a la possibilitat que la transferència moduli el desenvolupament.

Malgrat que els resultats són encoratjadors perquè s'han identificat trets comuns, cal tenir en compte la naturalesa qualitativa i d'exploració del treball, així com les limitacions metodològiques. Respecte les limitacions, la mostra heterogènia podria haver introduït variació desvinculada de la IL a través de factors com la situació en què es realitzaren els escrits, el nivell dels estudiants, la diferència dels enunciats i el context d'aprenentatge. A més, el nombre de participants per grup fluctuava entre vuit i disset. Fins i tot en el grup més nombrós hi havia massa heterogeneitat, ja que combinava parlants monolingües d'espanyol i bilingües espanyol-gallec. Aquestes diferències poden haver causat la sub- o sobreestimació dels errors. Així, doncs, caldria intentar replicar la recerca amb una mostra més nombrosa i homogènia.

Més enllà de les qüestions metodològiques, aquesta línia de recerca guanyaria interès amb una perspectiva quantitativa mitjançant un corpus de català com a llengua estrangera com el que planteja Cremades (2019). Comparant estudiants que hagin completat la mateixa tasca (com ara exàmens oficials) per a cada nivell, seria possible d'alliberar-nos de factors que afegeixen confusió instrumental innecessària. Després, caldria investigar altres aspectes lingüístics qualitativament, com a Toda-Cosi (2016), per proveir una base per a un qüestionari gramatical. Així també es podrien examinar els fenòmens que els estudiants eviten o que el context no afavoreix, tot proveint una visió més detallada de les ILs i les seves característiques. En aquest estudi hipotètic, el marc teòric més escaient seria la TP (Pienemann, 1998), que permetria comparar els resultats amb els d'estudis sobre altres llengües, com el de Bonilla (2015) sobre el castellà.

Així, doncs, aquest estudi conclou que la majoria de les diferències entre el sistema verbal del català i el de la interllengua dels aprenents que han participat en aquest estudi no es poden explicar unívocament a través de la transferència negativa des de les diverses L1. A més, l'aspecte, els verbs buits i les perífrasis verbals presenten característiques similars independentment de la llengua nativa dels aprenents. Tanmateix, aquestes observacions no són generalitzables sense que altres estudis també investiguin la qüestió, ja que la mostra amb què s'ha treballat és molt reduïda i heterogènia, cosa que permet tan sols observacions qualitatives i possiblement idiosincràtiques.

\section{Bibliografia}

Andersen, R. (1984). The one to one principle of interlanguage construction. Language Learning, 34, 77-95.

Andersen, R. (2002). The dimensions of pastness. Language acquisition and language disorders, 27, 79-106.

Bardel, C. i Falk, Y. (2007). The role of the second language in third language acquisition: The case of Germanic syntax. Second Language Research, 23(4), 459-484.

Bardovi-Harlig, K. i Comajoan-Colomé, L. (2020). The aspect hypothesis and the acquisition of L2 past morphology in the last 20 years: a state-of-the-scholarship review. Studies in Second Language Acquisition, 42(5), 1137-1167.

Bartning, I., i Forsberg Lundell, F. (2018). The last barriers in high-level L2 speech: Morphosyntax in focus. Dins K. Hyltenstam, I. Bartning i L. Fant (Eds.), High-level language proficiency in second language and multilingual contexts (pp. 50-72). Cambridge University Press.

Bonilla, C. L. (2015a). From number agreement to the subjunctive: Evidence for Processability 
Theory in L2 Spanish. Second Language Research, 31(1), 53-74.

Bonilla, C. L. (2015b). Instructing stages of processability theory in L2 Spanish. Dins K. Baten, A. Buyl, K. Lochtman i M. Van Herreweghe (Eds.), Theoretical and methodological developments in Processability Theory (pp. 205-238). John Benjamins.

Corder, S. P. (1967). The significance of learner's errors. International Review of Applied Linguistics in Language Teaching, 5(4),, 161-170.

Cremades, E. (26 d'abril de 2019). A tool for improving the studies on Catalan: the Catalan Corpus Learner. 17th Colloquium of the North American Catalan Society, University of Chicago, Chicago.

Ellis, R. (2005). Measuring implicit and explicit knowledge of a second language: A psychometric study. Studies in second language acquisition, 27(2), 141-172.

Ellis, N. C. (2016). Salience, cognition, language complexity, and complex adaptive systems. Studies in Second Language Acquisition, 38(2), 341-351.

Goldschneider, J. M. i DeKeyser, R. M. (2005). Explaining the "natural order of L2 morpheme acquisition" in English: A meta-analysis of multiple determinants. Language learning, 51(1), $1-50$.

Grañena, G. i Long, M. H. (2013). Age of onset, length of residence, language aptitude, and ultimate L2 attainment in three linguistic domains. Second Language Research, 29(3), 311343.

(2016) Gramàtica de la llengua catalana (2016). Institut d'Estudis Catalans.

Lado, R. (1973). Lingüística contrastiva: lenguas y culturas. Ediciones Alcalà.

Pienemann, M. (1998). Language processing and second language development: Processability theory. John Benjamins.

Pienemann, M. i Lenzing, A. (2019). Processability Theory. Dins B. VanPatten i J. Williams (Eds.) Theories in second language acquisition. Routledge.

Rothman, J. (2011). L3 syntactic transfer selectivity and typological determinacy: The typological primacy model. Second Language Research, 27(1), 107-127.

Rothman, J. (2015). Linguistic and cognitive motivations for the Typological Primacy Model (TPM) of third language (L3) transfer: Timing of acquisition and proficiency considered. Bilingualism: Language and Cognition, 18(2), 179-190.

Secretaria de Política Lingüística de la Generalitat de Catalunya. (2003, 2011). Programa de llengua catalana. Nivells inicial, bàsic i elemental. [En línia] https://llengua.gencat.cat/ ca/serveis/informacio_i_difusio/publicacions_en_linia/classific_temes/temes_materials_ didactics/programes_de_llengua_catalana_per_a_lensenyament_dadults [Consulta: 8 de març de 2016]

Selinker, L. (1992). Rediscovering interlanguage. Longman Publishers.

Sharwood Smith, M. (2020). Language transfer: a useful or pernicious concept? Second Language Research, https://doi.org/10.1177/0267658320941035

Slabakova, R. (2017). The scalpel model of third language acquisition. International Journal of Bilingualism, 21(6), 651-665.

Spadaro, K. (2013). Maturational constraints on lexical acquisition in a second language. Dins G. Granena i M. H. Long (Eds.), Sensitive periods, language aptitude, and ultimate L2 attainment (pp. 43-68). John Benjamins. 
Solà, J. (1981). "Ser" i "estar" en el català d'avui. Studia Neophilologica, 53(1), 149-176.

Toda-Cosi, M. (2016). Aproximació a la interllengua dels aprenents de català. [Treball de grau no publicat]. Departament de Filologia Catalana, Universitat Rovira i Virgili.

Tomlin, R. S., i Villa, V. (1994). Attention in cognitive science and second language acquisition. Studies in Second Language Acquisition, 16(2), 183-203.

Westergaard, M., Mitrofanova, N., Mykhaylyk, R. i Rodina, Y. (2017). Crosslinguistic influence in the acquisition of a third language: The Linguistic Proximity Model. International Journal of Bilingualism, 21(6), 666-682. 